\title{
Focus Group as a tool for a participatory construction and development of Integrated Fire Management strategies
}

\author{
Carolina Costa Rodrigues ${ }^{l}$, Wanderley Jorge da Silveira Junior ${ }^{l}$, Aloysio Souza de Moural, \\ Mariana Caroline Moreira Morelli ${ }^{1}$ e Marco Aurélio Leite Fontes ${ }^{l}$
}

${ }^{1}$ Federal University of Lavras (UFLA), Lavras, Brazil.

Contact email: carolinacrd@gmail.com, jjjuniorjf@hotmail.com, thraupidaelo@yahoo.com.br, marianaengflor@gmail.com, fontes@ufla.br

\begin{abstract}
Integrated Fire Management comprises a contemporary approach to fire management that combines sociocultural realities and ecosystems ecological needs with technological approaches to propose prescribed fires, thus preventing, monitoring and combating megafires. In this context, it is necessary to construct an integration between social actors related to the fire, as there are often divergences in perceptions and conflict regarding the fire use. The Focus Group is a strategy for collecting information from a focus theme that privileges a space for interaction between the group and the researcher / facilitator, which encourages participants to listen and share experiences. This study aimed to verify the experience of the Focus Group held in Carrancas, Minas Gerais, Brazil, in which are present different social actors aware of the occurrences and practices of fire management, in order to identify the difficulties and raise proposals about the fire use in natural areas management and conservation. Nine social actors participated, including traditional farmers, brigade members, people linked to tourism and public authorities. Participatory Rapid Diagnosis techniques were used, such as timeline, historical graph and participatory mapping, generating relaxation and involvement in activities. The dialogue made it possible to identify the traditional practice of controlled burning in rural ecosystems and the cultural changes that have contributed to the increase of megafires in recent years. The timeline and characterization of the largest fires, the survey of susceptible areas, and actions that should be prioritized for conservation of natural ecosystems were performed. The different fire scenarios (burnings and megafires) highlighted the different perceptions of social actors about their use, by the conflict between traditional farmers and brigade members, especially regarding fire management issues. The Focus Group proved to be effective in providing dialogue and greater interaction between social actors, reducing existing conflicts, generating reflection and subsidies to the construction of knowledge and management strategies, fire management and conservation of natural ecosystems.
\end{abstract}

Keywords: fire ethnoecology, methodology, participatory actions 